Originally published as:

Kaulitz, D., Mihica, D., Plesker, R., Geissler, A., Tönjes, R.R., Denner, J.

Absence of infection in pigs inoculated with high-titre recombinant PERV-A/C

(2011) Archives of Virology, 156 (4), pp. 707-710.

DOI: $10.1007 / s 00705-010-0896-5$

This is an author manuscript.

The definitive version is available at: http://www.springerlink.com/ 


\title{
Absence of infection in pigs inoculated with high-titre recombinant PERV-A/C
}

\author{
D. Kaulitz ${ }^{1}$, D. Mihica ${ }^{1}$, R. Plesker ${ }^{2}$, A. Geissler ${ }^{2}$, R. R. Tönjes ${ }^{2}$ and J. Denner ${ }^{1}$ \\ ${ }^{1}$ Robert Koch Institute, Berlin, Germany \\ ${ }^{2}$ Paul Ehrlich Institute, Langen, Germany
}

Email: DennerJ@rki.de

\begin{abstract}
Porcine endogenous retroviruses (PERVs) represent a risk for xenotransplantation using pig cells or organs since they are integrated in the genome of all pigs and infect human cells in vitro.

Recombinants between PERV-A and PERV-C have been described in pigs in vivo and found de novo integrated in the genome of somatic cells, but not in the germ line. To study whether PERV-A/C can infect and have a pathogenic effect in normal pigs, German landrace pigs were inoculated with hightitre PERV-A/C. No provirus integration was found in blood cells or in various tissues, and no antibody production was observed, indicating the absence of infection.
\end{abstract}

Xenotransplantation may help to overcome the shortage of allotransplants. However, the transplantation of cells, tissues or organs from pigs to humans may be associated with transmission of zoonotic porcine microorganisms. Porcine endogenous retroviruses (PERVs) represent a special risk, since they are integrated in the genome of all pigs, are released by normal pig cells and infect human cells in vitro (for review see Ref. [1]). Whereas PERV-A and PERV-B are human/polytropic viruses and are present in the genome of all pigs, PERV-C are ecotropic viruses and are present only in some pigs. Recombinants between PERV-A and PERV-C have been reported, which were generated in pigs in vivo and which were found de novo integrated in the genome of some pig cells, but not in the germ line, indicating that recombination took place during the lifetime of the animals [2-6]. PERV-A/C are characterised by high titres when compared with parental PERV-A [7], and when propagated on human cells, the titre increases further due to multimerisation of transcription factor NFY binding sites in the long terminal repeats (LTR) [8]. Similar changes in the LTR were observed, when PERV-A was propagated in human cells [8-10].

It is still unclear whether PERVs are associated with pathogenesis in pigs. PERVs have been isolated from a cell line derived from a malignant lymphoma [11], and an elevated expression of PERV in pig melanoma cells compared with the expression in normal skin cells has been reported [12], but it is unclear whether the virus was involved in tumour development. On the other hand, PERV particles have been isolated from normal pig kidney cell lines [13, 14]. In addition, integrated PERV-A/C has been detected in the spleen, but not in other organs, of animals with melanoma [12]. In order to analyse whether PERV-A/C can infect normal pigs and whether this infection has pathologic consequences, pigs were inoculated with high doses of PERV $/ 5^{\circ}$. This virus was derived from a recombinant PERV-A/C, called PERV $/ 3^{0}$ (kindly provided by C. Wilson [2]), which was passaged serially on human 293 cells. During the passages, the titre increased and an increase in the number of transcription factor NFY binding sites in the LTR was observed [8]. A 37-bp sequence containing the NFY binding site ATTGG is present once in PERV $/ 3^{\circ}$, twice in PERV $/ 4^{\circ}$ and 5 times in PERV $/ 5^{\circ}$ [8]. After long-term cultivation on human 293 cells without selection pressure (e.g., without passaging onto uninfected 293 cells) the cells produced a mixture consisting of PERV $-5^{\circ}$ and PERV/LT (long term) characterised by the loss of two NFY binding sites and one CCAAT protein (CBEP) binding site by deletion [15].

Pigs were inoculated with the supernatant of 293 cells producing a mixture of PERV/5 ${ }^{\circ}$ and PERV-LT. In order to characterize the proviruses, cellular DNA was isolated (DNeasy Blood and Tissue Kit, QIAGEN) and PCR was performed using the primer pairs PERVenvAfor (TGGAAAGATTGGCAACAGCG) and rev (AGTGATGTTAGGCTCAGTGG) [16] and LTRfor 
(TCTTGGTGACAACATGTCTC) and rev (AGTGTGGAGTCGGGACAGCT) [15]. Electrophoresis was performed in a $1 \%$ agarose gel. As expected, analysis of the LTR showed that a mixture of PERV $/ 5^{\circ}$ and PERV/LT had been produced (Fig. 1). Five hundred $\mathrm{ml}$ of viral supernatant corresponding to $6.4 \times 10^{6}$ infectious particles, as shown by titration on 293 cells, were inoculated i.p. into each of two German landrace pigs (\#5 and \#17) obtained from a farm in Germany. To measure the virus titer, 293 cells were cultured in microtiter plates $\left(1.5 \times 10^{5}\right.$ cells/well), dilutions of virus-containing supernatant were added, and after $72 \mathrm{~h}$, DNA was collected after cell lysis by freezing/thawing and treatment with proteinase $K$. Proviral DNA was quantified by real-time PCR using the gag primers

TCCAGGGCTCATAATTTGTC and TGATGGCCATCCAACATCGA and the probe FAM-

AGAAGGGACCTTGGCAGACTTTCT-BHQ1. A duplex PCR was performed using primers and a probe specific for GAPDH (GGCGATGCTGGCGCTGAGTAC, TGGTCCACACCCATGACGA, HEXTTCACCACCATGGAGAAGGCTGGG-BHQI). The $\triangle \mathrm{Ct}$ method was used to normalise PERV integration to the GAPGH gene copy number, and neutralisation was expressed as percent inhibition of provirus integration by the immune serum compared with the preimmune serum.

A third animal (\#6) was kept as a negative control. Like all pigs, animals 5, 6 and 17 carried PERV-A (Fig. 2) and PERV-B (not shown) in their genome, as shown by PCR. They did not carry PERV-C and were therefore unable to generate PERV-A/C. Blood was taken from the animals 1, 2, 3 and 4 months after inoculation and analysed for the presence of PERV-A/C by PCR using the primers PERV-A VRBF (CCTACCAGTTATAATCAATTTAATTATGGC) and PERV-C env TMR (CTCAAACCACCCTTGAGTAGTTTCC) [3]. This PCR recognizes 0.00026 copies per cell, as estimated by dilution of a PERV-A/C plasmid with pig DNA. After four months, the animals were sacrificed, organs were taken, and the DNA was isolated and analysed for the presence of PERV-A/C (Fig. 2). PERV-A/C was not detected in any of the samples, indicating that the virus did not infect either animal. To study whether PERV-specific antibodies were produced, lysates of PERV-A/C particles pelleted by ultracentrifugation through a sucrose cushion were used, and proteins were subjected to SDS-PAGE in 10\% gels using a tricine-buffered system [17] and transferred to PVDF membranes (Millipore, Bedford, MA, USA) by semidry electroblotting. Nonspecific binding was blocked using $0.05 \%$ Tween 20 and $5 \%$ milk in PBS for 1 hour at room temperature. Sera from pigs after inoculation of PERV-A/C were used at a 1:100 dilution, goat sera specific for the transmembrane envelope protein p15E (\#355), for the core protein p27Gag (\#14 [18]) and for the surface envelope protein gp70 (\#62 [19]) were used at a 1:250 dilution (Fig. 3). No antibodies were detected, indicating the absence of infection.

Despite the fact that PERV-A/C infects pig lowa cells in vitro (not shown), the result of the experiment demonstrate that this virus is not easily transmissible from one pig to another, and this is in agreement with previous studies showing that it is difficult to infect animals with PERV. Although mink cells [20] and cells from non-human primates [21-23] can be infected with PERV in vitro, all attempts to infect animals in vivo have failed: provirus integration and PERV-specific antibodies were not detected in minks [20] or in baboons, pig-tailed macaques and rhesus monkeys inoculated with high-titre PERV ${ }^{0}$ and treated daily with three different immunosuppressive drugs [23].

How can the absence of infection be explained? First, pigs may express PERV-A Env proteins in their tissues and prevent infection with PERV-A/C due to receptor interference. Second, PERV may be eliminated by innate immunity. The complement system and preformed antibodies may be involved in this process [24, 25]. In addition, intracellular restriction factors may prevent virus replication [26-28]. Third, the amount of virus used for inoculation may have been too low. However, the number of infectious particles $\left(6.4 \times 10^{6}\right)$ was much higher than what has been used for infection of cats with feline leukaemia virus (FeLV) and mice with murine leukaemia virus (MuLV). Between $1 \times 10^{4}$ TCID50 [29] and $1 \times 10^{6} \mathrm{ffu}$ [30] FeLV was sufficient to infect cats oronasally, and $2 \times 10^{4} \mathrm{ffu}$ was used for successful infection of mice with MuLV [31]. The absence of antibodies may be explained either by the absence of replication or by the fact that pigs are immunologically tolerant to PERVs, as they are endogenous. Since PERV-C-free animals were used in these studies, this tolerance has to include closely related Env sequences of PERV-C. On the other hand, antibodies against the human endogenous retrovirus HERV-K, which is endogenous in humans, have been found in patients expressing HERV-K in melanomas [32].

The negative results of the infection experiments, including those described here using high-titre PERV, may explain the absence of infection in pig-to-non-primate xenotransplantations as well as in the first clinical xenotransplantations, which included liver failure patients receiving ex vivo perfusions of porcine hepatocytes, and also in butchers, who often have blood-blood contact with pigs (for review 
see Ref. [33]).

\section{References}

1. Wilson CA (2008) Porcine endogenous retroviruses and xenotransplantation. Cell Mol Life Sci 65:3399-3412

2. Wilson C, Wong S, VanBrocklin M, Federspiel M (2000) Extended analysis of the in vitro tropism of porcine endogenous retrovirus. J Virol 74:49-56

3. Wood JC, Quinn G, Suling KM, Oldmixon BA, Van Tine BA, Cina R, Arn S, Huang CA, Scobie L, Onions DE, Sachs DH, Schuurman HJ, Fishman JA, Patience C (2000) Identification of exogenous forms of human-tropic porcine endogenous retrovirus in miniature swine. J Virol 78:2494-2501

4. Bartosch B, Stefanidis D, Myers R, Weiss R, Patience C, Takeuchi Y (2004) Evidence and consequence of porcine endogenous retrovirus recombination. J Virol 78:13880-13890

5. Martin SI, Wilkinson R, Fishman JA (2006) Genomic presence of recombinant porcine endogenous retrovirus in transmitting miniature swine. J Virol 3:91-96

6. Denner J (2008) Recombinant porcine endogenous retroviruses (PERV-A/C): a new risk for xenotransplantation? Arch Virol 153:1421-1426

7. Harrison I, Takeuchi Y, Bartosch B, Stoye JP (2004) Determinants of high titer in recombinant porcine endogenous retroviruses. J Virol 78:13871-13879

8. Denner J, Specke V, Thiesen U, Karlas A, Kurth R (2003) Genetic alterations of the long terminal repeat of an ecotropic porcine endogenous retrovirus (PERV) during passage in human cells. Virology 314:125-133

9. Scheef G, Fischer N, Krach U, Tönjes RR (2001) The number of a U3 repeat box acting as an enhancer in long terminal repeats of polytropic replication-competent porcine endogenous retroviruses dynamically fluctuates during serial virus passages in human cells. J Virol 75(15):6933-6940 10. Scheef G, Fischer N, Flory E, Schmitt I, Tönjes RR (2002) Transcriptional regulation of porcine endogenous retroviruses released from porcine and infected human cells by heterotrimeric protein complex NF-Y and impact of immunosuppressive drugs. J Virol 76(24):12553-12563

11. Suzuka I, Sekiguchi K, Kodama M (1985) Some characteristics of a porcine retrovirus from a cell line derived from swine malignant lymphomas. FEBS Lett 183:124-128

12. Dieckhoff B, Puhlmann J, Büscher K, Hafner-Marx A, Herbach N, Bannert N, Büttner M, Wanke R, Kurth R, Denner J (2007) Expression of porcine endogenous retroviruses (PERVs) in melanomas of Munich miniature swine (MMS). Troll Vet Microbiol 123:53-68

13. Breese SS Jr (1970) Virus-like particles occurring in cultures of stable pig kidney cell lines. Arch Gesamte Virusforsch 30:401-404

14. Armstrong JA, Porterfield JS, Madrid ATD (1971) C-type virus particles in pig kidney cell lines. J Gen Virol 10:195-198

15. Karlas A, Irgang M, Votteler J, Specke V, Özel M, Kurth R, Denner J (2010) Characterisation of a human cell-adapted porcine endogenous retrovirus PERV-A/C. Ann Transplant 15(2):45-54

16. Le Tissier P, Stoye JP, Takeuchi C, Patience YC, Weiss RA (1997) Two sets of human-tropic pig retrovirus. Nature 389: 681-682

17. Tacke S, Bodusch K, Berg A, Denner J (2001) Sensitive and specific immunological detection methods for porcine endogenous retroviruses applicable to experimental and clinical xenotransplantation. Xenotransplantation 8:125-135

18. Irgang M, Sauer IM, Karlas A, Zeilinger K, Gerlach JC, Kurth R, Neuhaus P, Denner J (2003) Porcine endogenous retroviruses (PERVs): no infection in patients treated with a bioreactor based on porcine liver cells. J Clin Virol 28:141-154

19. Garkavenko O, Dieckhoff B, Wynyard S, Denner J, Elliott RB, Tan PL, Croxson MC (2008) Absence of transmission of potentially xenotic viruses in a prospective pig to primate islet xenotransplantation study. J Med Virol 80:2046-2052

20. Specke V, Plesker R, Coulibaly C, Boller K, Denner J (2002) Productive infection of a mink cell line with porcine endogenous retroviruses (PERVs) and lack of transmission to minks in vivo. Arch Virol 147:305-319

21. Ritzhaupt A, van der Laan LJW, Salomon DR, Wilson CA (2002) Porcine endogenous retrovirus infects but does not replicate in nonhuman primate cells and cell lines. J Virol 76:11312-11320 22. Blusch JH, Patience C, Takeuchi Y, Templin C, Roos C, Von Der Helm K, Steinhoff G, Martin U (2000) Infection of nonhuman primate cells by pig endogenous retrovirus. J Virol 74:7687-7690 23. Specke V, Plesker R, Wood J, Coulibaly C, Suling K, Patience C, Kurth R, Schuurman HJ, Denner $\mathrm{J}$ (2009) No in vivo infection of triple immunosuppressed non-human primates after inoculation with high titers of porcine endogenous retroviruses (PERVs). Xenotransplantation 16:34-44 
24. Lachmann PJ, Davies A (1997) Complement and immunity to viruses. Immunol Rev 159:69 25. Ochsenbein AF, Zinkernagel RM (2000) Natural antibodies and the complement link innate and acquired immunity. Immunol Today 21:624

26. Towers GJ (2007) The control of viral infection by tripartite motif proteins and cyclophilin A. Retrovirology 4:40

27. Goilar-Gaur R, Strebel K (2008) HIV-1 Vif, APOBEC, and intrinsic immunity. Retrovirology 5:51 28. Dörrschuck E, Münk C, Tönjes RR (2008) APOBEC3 proteins and porcine endogenous retroviruses. Transplant Proc 40(4):959-961

29. Torres AN, O'Halloran KP, Larson LJ, Schultz RD, Hoover EA (2010) Feline leukemia virus immunity induced bywhole inactivated virus vaccination. Vet Immunol Immunopathol 134(1-2):122131

30. Major A, Cattori V, Boenzli E, Riond B, Ossent P, Meli ML, Hofmann-Lehmann R, Lutz H (2010) Exposure of cats to low doses of FeLV: seroconversion as the sole parameter of infection. Vet Res 41(2): 17

31. Evans LH, Lavignon M, Peterson K, Hasenkrug K, Robertson S, Malik F, Virtaneva K (2006) In vivo interactions of ecotropic and polytropic murine leukemia viruses in mixed retrovirus infections. J Virol. 80(10):4748-4757

32. Büscher K, Trefzer U, Hofman M, Sterry W, Kurth R, Denner J (2005) Expression of human endogenous retrovirus $\mathrm{K}$ in melanomas and melanoma cell lines. Cancer Res 65(10):4172-4180 33. Denner J, Schuurman H, Patience C (2009) The International Xenotransplantation Association consensus statement on conditions for undertaking clinical trials of porcine islet products in type 1 diabetes-chapter 5: strategies to prevent transmission of porcine endogenous retroviruses. Xenotransplantation 16:239-248

\section{Figures}

Figure 1. Characterisation of the LTR of the virus used for inoculation. 1-3 control plasmids, 1- PERV$3^{\circ}$, containing one 37 -bp sequence, which contains the NFY binding site, 2- PERV-4 $4^{\circ}$, containing two 37-bp sequences, 3 - PERV- $5^{\circ}$ containing 5 of the 37-bp sequences, 4- 293 cells infected with PERV$5^{\circ}$ and used for virus production

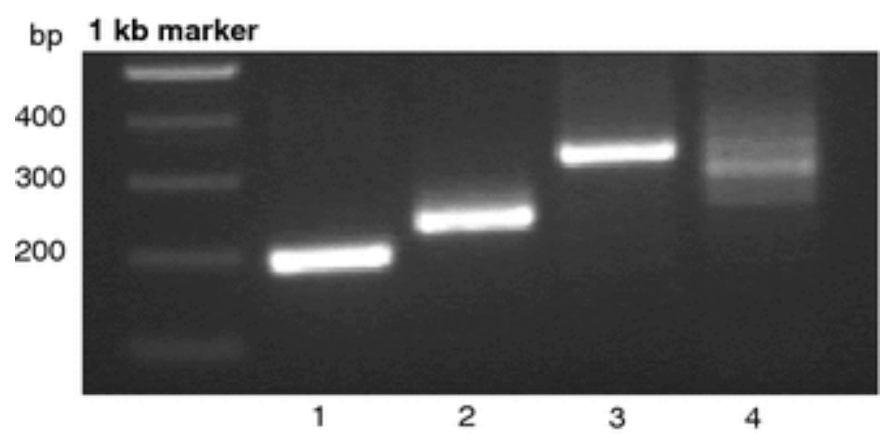


Figure 2. PCR analysis of pigs before and at different time points after inoculation with $P E R V-A / C$ as well as of the organs of animal 17, using primers specific for PERV-A/C and PERV-A. Animal 6 was untreated (not tested in month 0), and animals 5 and 17 received PERV-A/C. 1 - heart, 2 - muscle, 3 liver, 4 - kidney, 5 - spleen, 6 - lymph node, 7 - lung, 8 - skin, 9 - 293 cells infected with PERV-5

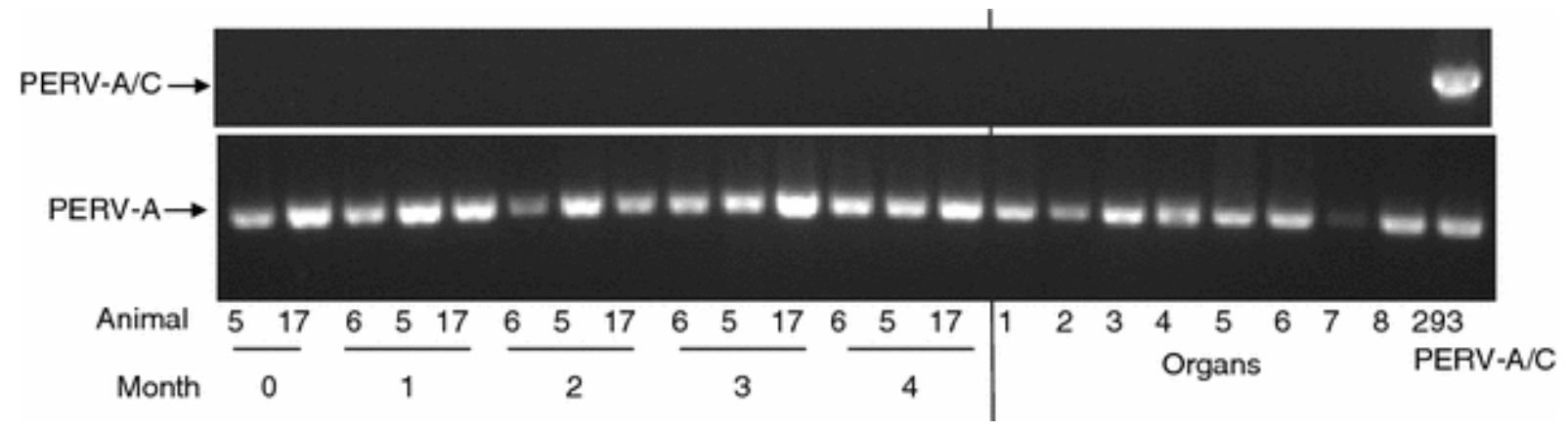

Figure 3. Western blot analysis of sera from three pigs collected four months after inoculation with PERV-A/C. Animals 5 and 17 were inoculated; animal 6 was the control. As antigen a lysate of purified PERV $-5^{\circ}$ was used; the sera were diluted 1:100. 1 - Goat sera against p15E, 2 - gp27Gag and 3 gp70, 4 - pig 6, 5 - pig 5, 6 - pig 17. In lane $C$, the immune response of a pig against $E$. coli lysate is shown, demonstrating the functionality of the anti-pig antibody

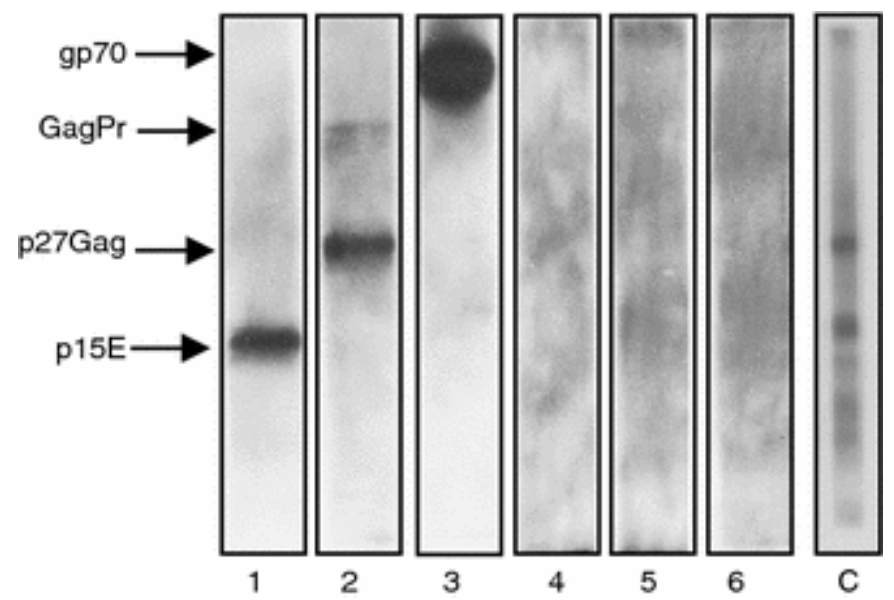

